\title{
KinerJa FungSi Terminal Giri AdiPURA dalam SiSTem Transportasi DI KABUPATEN WONOGIRI
}

\author{
Nur Laila Fitriana, Galing Yudana, Winny Astuti \\ Program Studi Perencanaan Wilayah dan Kota \\ Fakultas Teknik \\ Universitas Sebelas Maret, Surakarta \\ email: nur.lf@student.uns.ac.id
}

\begin{abstract}
Terminal is included in the transportation network system which functions as a place for passengers to take the bus and a place to drop the passengers. Terminal is also the element of spatial arrangement which influences the structure and system of a town's movement. The development of Giri Adipura Terminal in Singodutan Village which was done from 2010 to 2014 is aimed to recover the performance of previous terminal and to develop the surrounding area. Phenomenon which was happened in Giri Adipura Terminal is there were still many passengers who were not utilizing the terminal function and the public transportations were not entering the terminal in order. This research was done to know the performance of Giri Adipura Terminal function in transportation system in Wonogiri Regency. The used research method was quantitative with deductive approach. The used analysis technique was scoring, by determined the parameter and indicator in each variabel. The result of scoring calculation from the performance of Giri Adipura Terminal function in transportation system in Wonogiri Regency was 9.33. Based on the performance of terminal function category, 9.33 score was in range of 6.68-9.35, so it was included in the average performance category. Thus, the performance of Giri Adipura Terminal function in transportation system in Wonogiri Regency has not reach a good performance yet and it needs some things which should be done to reach that performance. For the performance of each variable, variables which were in the good performance category were accessibility and traffic management. Meanwhile, variables which were in the average category were terminal service and transportation movement access.
\end{abstract}

Keywords: performance, terminal function, transportation system

\section{PENDAHULUAN}

Sistem transportasi terdiri dari sistem kegiatan, sistem jaringan, dan sistem pergerakan. Sistem kegiatan berkaitan dengan pola ruang atau tata guna lahan tempat kegiatan manusia dilakukan. Sistem jaringan berkaitan dengan prasarana transportasi yang dibutuhkan untuk melakukan perpindahan. Sedangkan sistem pergerakan berkaitan dengan arus dan pola pergerakan lalu lintas yang dihasilkan dari sistem kegiatan dan sistem jaringan (Tamin, 2000). Agar sistem transportasi ini dapat berjalan dengan lancar, terdapat beberapa elemen yang perlu diperhatikan yaitu kendaraan, jalan, terminal, dan muatan (Adisasmita, 2011). Seringkali masing-masing elemen di atas tidak berfungsi sebagaimana mestinya sehingga menimbulkan permasalahan.

Salah satu elemen transportasi yang terkait dengan ilmu perencaaan wilayah dan kota adalah terminal. Terminal adalah simpul transportasi yang menempati tata guna lahan tertentu dan berfungsi mempertemukan antara muatan (manusia dan barang) dengan moda transportasi tertentu. Dalam bidang penataan ruang, terminal merupakan prasarana transportasi berupa tempat kendaraan umum berpangkal, tempat penumpang atau barangbarang naik-turun atau pindah kendaraan (Direktorat Jenderal Cipta Karya Departemen Pekerjaan Umum, 1997 dalam Yusni Mustari dan Dahri Kuddu, 2011). Untuk itu, sejak awal akan dibangunnya sebuah terminal perlu memperhatikan berbagai aspek seperti aspek ekonomi, aspek sosial, aspek tata ruang, aspek lingkungan hidup, dan aspek peraturan perundang-undangan. Pendekatan komprehensif dan pertimbangan kondisi di masa depan tidak dapat dikesampingkan agar infrastruktur ini dapat berfungsi sesuai harapan (Adisasmita, 2011).

Terminal Giri Adipura merupakan terminal tipe A yang memiliki peran melayani 
kendaraan umum untuk angkutan antarkota antarprovinsi (AKAP) yang dipadukan dengan pelayanan angkutan antarkota dalam provinsi (AKDP), angkutan perkotaan (Angkot), dan atau angkutan perdesaan (Angkudes). Terminal ini terletak di Kecamatan Selogiri yang dijelaskan dalam RTRW Kabupaten Wonogiri Tahun 2011-2031 menjadi Pusat Pelayanan Kawasan (PPK) dalam sistem perkotaan Kabupaten Wonogiri.

Pengembangan Terminal Tipe A Giri Adipura di Desa Singodutan yang dilakukan dari tahun 2010 hingga tahun 2014 ditujukan untuk memperbaiki kinerja terminal sebelumnya dan mengembangkan kawasan sekitarnya. Fenomena yang terjadi di Terminal Giri Adipura adalah masih banyak penumpang yang tidak memanfaatkan fungsi terminal dan angkutan umum penumpang tidak tertib masuk ke dalam terminal. Rumusan masalah dari kondisi tersebut yaitu,

"Bagaimana kinerja fungsi Terminal Giri Adipura dalam sistem transportasi di Kabupaten Wonogiri?"

\section{KAJIAN TEORI}

Fungsi merupakan suatu kegiatan atau tujuan dasar yang ditujukan untuk orang atau hal. Adapun menurut KBBI, fungsi adalah kegunaan dari suatu hal. Fungsi terminal adalah kegunaan terminal dalam bentuk kegiatan yang ditujukan untuk penggunanya. Sebagai prasarana transportasi yang terhubung dalam sistem jaringan transportasi, terminal memiliki beberapa fungsi. Menurut Morlok (1984), terminal memiliki fungsi-fungsi yang dapat dijabarkan sebagai berikut.

1. Memuat penumpang atau barang ke atas kendaraan serta membongkar. Memindahkan dari satu kendaraan ke kendaraan lain,

2. Menampung penumpang atau barang dari waktu tiba sampai waktu berangkat kemungkinan untuk memproses barang, dan menyediakan kenyamanan penumpang (misalnya pelayanan makan, dan sebagainya),

3. Menyiapkan dokumentasi perjalanan, menimbang muatan, memilih rute, menjual tiket penumpang, memeriksa pesanan tempat.

4. Mengumpulkan penumpang dan barang di dalam grup-grup berukuran ekonomis untuk diangkut dan untuk menurunkan mereka setelah tiba di tempat tujuan.
Selanjutnya, Wright dan Ashford (1998) dalam (Parapat dkk., 2005) memiliki pendapat sendiri tentang fungsi terminal, yaitu:

1. Sebagai titik konsentrasi (traffic consentration) dimana penumpang berkumpul dari segala arah untuk melanjutkan perjalanan ke tempat tujuan;

2. Sebagai titik dispersi (classification and sorting) dimana penumpang menyebar sesuai dengan tujuannya;

3. Sebagai titik tempat berganti moda angkutan (traffic interchange) dimana terjadi perpindahan moda angkutan yang dilakukan oleh penumpang untuk melanjutkan perjalanan; dan

4. Sebagai titik pusat layanan (service avaibility) untuk bongkar muat (loading and unloading), penyimpanan jangka pendek (storage) dan tempat proses untuk pembelian tiket, menunggu, menyimpan bawaan penumpang dan prosedur lain.

Menurut Kamus Besar Bahasa Indonesia (KBBI), kinerja memiliki pengertian kemampuan kerja dan sesuatu yang dicapai. Pendapat lain mengatakan bahwa kinerja merupakan tingkat keberhasilan melaksanakan tugas serta kemampuan dalam mencapai tujuan yang ditetapkan. Kinerja akan dikatakan baik apabila tujuan yang diinginkan dapat tercapai (Donelly, Gibson and Ivancevich, 1994). Untuk mengukur kinerja fungsi terminal dalam sistem transportasi, terdapat beberapa indikator yang digunakan yaitu:

1. Aksesibilitas adalah ukuran yang menentukan kenyamanan dan kemudahan dalam mencapai sebuah lokasi melalui sistem jaringan transportasi (Black, 1981) dalam (Tamin, 2000). Menurut Keputusan Menteri Perhubungan No 31 Tahun 1995, lokasi terminal harus berada di jalan arteri dengan kelas jalan sekurang-kurangnya kelas IIIA.

2. Efisiensi retribusi dilihat dari perbandingan manfaat yang diberikan dengan pengorbanan yang dilakukan. Dalam hal ini, terminal akan semakin efisien jika memberikan manfaat tertentu dengan pengorbanan minimum (Sistem Transportasi Nasional, 2005).

3. Keterpaduan dapat dilihat dari pergantian intermoda dan antarmoda (Sistem Transportasi Nasional, 2005). Pergantian intermoda adalah pergantian moda dengan moda yang sama. Dalam Keputusan Menteri No 31 Tahun 1995 pelayanan terminal hanya ditujukan untuk 
angkutan umum darat (bus) sehingga bentuk keterpaduan dilihat dari pendekatan sistem jaringan trayek yang saling mendukung.

4. Kapasitas dikatakan mencukupi apabila kapasitas prasarana transportasi memenuhi permintaan pengguna jasa (Sistem Transportasi Nasional, 2005). Kapasitas terminal dalam penelitian ini diukur dengan membandingkan luas parkir kendaraan dengan standar yang ada yaitu dari Lembaga Pengabdian Universitas Gajah Mada Pusat Pengembangan Teknologi Tepat (1994).

5. Keteraturan berkaitan dengan penggunaan waktu yang efektif dengan diberlakukannya jadwal. Ukuran dari parameter ini adalah jumlah sarana transportasi yang berjadwal dibandingkan dengan jumlah sarana yang beroperasi (Sistem Transportasi Nasional, 2005). Kendaraan berjadwal seharusnya dapat beroperasi sesuai dengan waktu yang tertulis dalam jadwal sehingga penumpang tidak harus menunggu lama.

6. Keamanan adalah tingkat aman dalam melakukan suatu perjalanan. Menurut Warpani (1990) keamanan meliputi terhindar dari kecelakaan, badan terlindung dari luka benturan, serta bebas dari kejahatan. Dalam Peraturan Menteri Perhubungan No 40 Tahun 2015, keamanan meliputi ketersediaan fasilitas keamanan dan petugas keamanan.

7. Kenyamanan di dalam akan terasa terminal bila dilengkapi dengan berbagai fasilitas yang memberikan kenyamanan bagi penumpangnya, seperti ketersediaan tempat duduk dan sistem pengaturan udara (Warpani, 1990). Fasilitas ini dinilai dari ketersediaan dan kualitasnya sehingga penyelenggaraan terminal dapat berjalan dengan optimal. Jenis-jenis fasilitas yang harus ada di terminal menyesuaikan dengan Keputusan Menteri Perhubungan No 31 Tahun 1995.

8. Kesetaraan merupakan hal yang penting dipikirkan karena pada dasarnya seluruh masyarakat harus dapat menikmati fasilitas yang dibangun oleh pemerintah. Dalam Peraturan Menteri Perhubungan No 40 Tahun 2015, fasilitas yang disediakan untuk menunjang pelayanan kesetaraan di terminal meliputi keberadaan ramp check, kursi roda, toilet khusus difabel serta ruang ibu menyusui.
9. Lancar dan cepat yang dapat dicapai dengan terwujudnya perjalanan dalam waktu tempuh yang singkat dengan tingkat keselamatan yang tinggi (Sistem Transportasi Nasional, 2005).

\section{METODE PENELITIAN}

Jenis pendekatan yang digunakan dalam penelitian ini adalah pendekatan deduktif yang berpedoman dari teori-teori yang ada. Sedangkan penelitian ini termasuk penelitian kuantitatif. Hal itu berarti dilakukan dengan analisis statistik dari data yang didapat untuk diterjemahankan ke dalam angka-angka. Variabel-variabel yang muncul dalam penelitian ini disarikan dari teori. Variabel dalam penelitian ini dapat dilihat pada Tabel 1 .

Tabel 1. Variabel Penelitian

\begin{tabular}{|l|l|}
\hline Variabel & Sub variabel \\
\hline Simpul Lalu & Aksesibilitas \\
\cline { 2 - 2 } Lintas & Efisiensi Retribusi \\
\hline Akses \\
$\begin{array}{l}\text { Perpindahan } \\
\text { Moda }\end{array}$ & Keterpaduan \\
\cline { 2 - 2 } $\begin{array}{l}\text { Pelayanan } \\
\text { Terminal }\end{array}$ & Kapasitas \\
\cline { 2 - 2 } & Keteraturan \\
\cline { 2 - 2 } $\begin{array}{l}\text { Manajemen Lalu } \\
\text { Lintas }\end{array}$ & Keamanan \\
& Kesetaraan \\
\hline
\end{tabular}

Teknik pengumpulan data yang digunakan dalam penelitian ini adalah teknik pengumpulan data primer dan sekunder. Teknik pengumpulan data primer meliputi wawancara keteraturan angkutan umum, observasi kondisi fasilitas di terminal, serta kuesioner penumpang dan operator bus terkait manajemen lalu lintas. Teknik pengumpulan data primer, yaitu data yang berasal dari dokumen instansi seperti data trayek angkutan umum di sekitar terminal, rencana tapak terminal, data fasilitas terminal, data target dan pendapatan retribusi terminal, peta jaringan jalan, dan jumlah angkutan umum yang beroperasi di terminal.

Populasi dari penelitian ini adalah penumpang dan operator bus yang berpotensi memanfaatkan Terminal Giri Adipura. Kedua populasi ini adalah obyek dari penelitian ini untuk mengukur sasaran penelitian. Sample dari penduduk ini adalah sebagai berikut.

Jumlah penumpang yang masuk ke Terminal Giri Adipura pada tahun 2015 adalah 957.134 orang. Sedangkan jumlah bus yang masuk ke Terminal Giri Adipura pada tahun 2015 adalah 67.228 bus. Populasi operator bus dihitung dari rata-rata bus yang masuk ke 
Nur Laila, Galing Yudana, Winny Astuti, Kinerja Fungsi...

terminal pada tahun 2015 dalam satu hari yaitu 184 bus. Sedangkan populasi penumpang dihitung dari rata-rata penumpang yang masuk ke terminal pada tahun 2015 dalam satu hari yaitu 2.622 penumpang. Perhitungan sampel dilakukan berdasarkan rumus Slovin (Ariola et al, 2006), yaitu:

$$
n=\frac{N}{1+N \cdot d^{2}}
$$

$\mathrm{n} \quad=$ Jumlah sampel

$\mathrm{N}=$ Jumlah populasi

$\mathrm{D}=$ tingkat kesalahan maksimum pengambilan sampel $10 \%(0,1)$

Berdasarkan hasil perhitungan maka jumlah sampel untuk penumpang adalah 96 sedangkan jumlah sampel untuk sopir bus adalah 65 .

Metode penelitian ini menggunakan teknik analisis sebagai berikut.

1. Analisis kinerja fungsi terminal Giri Adipura dalam sistem transportasi dengan cara skoring masing-masing parameter pada sub variabel. Indikator yang dibentuk dari setiap parameter yaitu baik, sedang, dan buruk. Indikator ditentukan berdasarkan teori maupun pendekatan lainnya, seperti asumsi maupun berdasar penelitian sebelumnya. Setiap variabel memiliki skor 3 untuk kategori baik, skor 2 untuk kategori sedang, dan skor 1 untuk kategori buruk. Skor ini kemudian dibagi sesuai dengan jumlah parameternya. Kategori kinerja dari parameter pada tiap variabel ditunjukan pada Tabel 2.

Tabel 2. Skoring Variabel

\begin{tabular}{|c|c|c|c|c|}
\hline \multirow{2}{*}{ Sub Variabel } & \multirow{2}{*}{ Parameter } & \multicolumn{3}{|c|}{ Skor } \\
\hline & & Baik & edang & Buruk \\
\hline \multicolumn{5}{|c|}{ 1. Variabel Simpul Lalu Lintas } \\
\hline Aksesibilitas & \begin{tabular}{|l|} 
Letak \\
terminal \\
menurut \\
klasifikasi \\
jalan
\end{tabular} & $3 / 2$ & 1 & $1 / 2$ \\
\hline Efisiensi & $\begin{array}{l}\text { Tingkat } \\
\text { efisiensi } \\
\text { retribusi } \\
\text { terminal }\end{array}$ & $3 / 2$ & 1 & $1 / 2$ \\
\hline \multicolumn{5}{|c|}{ 2. Variabel Akses Perpindahan Moda } \\
\hline Keterpaduan & \begin{tabular}{|l|} 
Integrasi \\
pelayanan \\
angkutan \\
umum lokal \\
dan regional \\
di terminal \\
\end{tabular} & 1 & $2 / 3$ & $1 / 3$ \\
\hline Kapasitas & $\begin{array}{l}\text { Ketersediaan } \\
\text { luas ruang } \\
\text { parkir }\end{array}$ & 1 & $2 / 3$ & $1 / 3$ \\
\hline
\end{tabular}

\begin{tabular}{|l|l|l|l|l|}
\hline \multirow{2}{*}{ Sub Variabel } & Parameter & \multicolumn{2}{|l|}{ Skor } \\
\cline { 2 - 5 } & Baik & edang & 3uruk \\
\hline Keteraturan & $\begin{array}{l}\text { Ketersediaan } \\
\text { angkutan } \\
\text { umum } \\
\text { berjadwal di } \\
\text { terminal }\end{array}$ & 1 & $2 / 3$ & $1 / 3$ \\
\hline 3. Variabel Pelayanan Terminal & & & \\
\hline Keamanan & $\begin{array}{l}\text { Ketersediaan } \\
\text { fasilitas dan } \\
\text { petugas } \\
\text { keamanan }\end{array}$ & 1 & $2 / 3$ & $1 / 3$ \\
\hline Kenyamanan & $\begin{array}{l}\text { Kelengkapan } \\
\text { dan kondisi } \\
\text { fasilitas di } \\
\text { terminal }\end{array}$ & 1 & $2 / 3$ & $1 / 3$ \\
\hline Kesetaraan & $\begin{array}{l}\text { Ketersediaan } \\
\text { fasilitas bagi } \\
\text { difabel dan } \\
\text { ibu } \\
\text { menyusui }\end{array}$ & 1 & $2 / 3$ & $1 / 3$ \\
\hline 4. Variabel Manajemen Lalu Lintas & $\begin{array}{l}\text { Kelancaran } \\
\text { lalu lintas di } \\
\text { luar terminal }\end{array}$ & $3 / 2$ & 1 & $1 / 2$ \\
\hline $\begin{array}{l}\text { Lancar dan } \\
\text { cepat }\end{array}$ & $\begin{array}{l}\text { Sirkulasi di } \\
\text { terminal }\end{array}$ & $3 / 2$ & 1 & $1 / 2$ \\
\hline
\end{tabular}

Setelah ditentukan skor di atas, kemudian dilakukan analisis keseluruhan untuk mengetahui kinerja fungsi Terminal Giri Adipura. Dalam menentukan kinerja fungsi Terminal Giri Adipura ke dalam kategori baik, sedang, dan buruk dilakukan perhitungan interval dengan cara mengurangi nilai maksimal dan nilai minimal dari tabel pembobotan.

Interval $=\frac{(\Sigma \text { skor max })-(\Sigma \text { skor }}{\text { min })}$

Interval $=\frac{4)}{3}$

Interval $=\quad 2,67$

Setelah didapatkan nilai interval, maka dapat diketahui kategori hasil skoring sebagai berikut.

Baik : jika nilainya $9,36 \leq \mathrm{x} \leq 12$

Sedang : jika nilainya $6,68 \leq \mathrm{x} \leq 9,35$

Buruk : jika nilainya $4 \leq \mathrm{x} \leq 6,67$

2. Analisis skoring kinerja dari tiap variabel dengan cara menjumlahkan skor dari parameter yang ada di tiap variabel seperti dalam Tabel 2. Selanjutnya skor tersebut disesuaikan dengan kategori kinerja tiap variabel yang dihitung dengan cara mencari interval. Berikut ini 
merupakan perhitungan interval untuk menyusun kategori kinerja tiap variabel.

$$
\begin{aligned}
\text { Interval } & =\frac{\left(\sum \text { skor max }\right)-\left(\sum \text { skor min }\right)}{\text { Jumlah Kelas }} \\
\text { Interval } & =\frac{(3-1)}{3} \\
\text { Interval } & =0,67
\end{aligned}
$$

Dari perhitungan di atas maka kategori kinerja untuk masing-masing variabel adalah sebagai berikut.

Baik : jika nilainya $2,36 \leq \mathrm{x} \leq 3$

Sedang : jika nilainya $1,68 \leq \mathrm{x} \leq 2,35$

Rendah : jika nilainya $1 \leq \mathrm{x} \leq 1,67$

\section{HASIL PENELITIAN}

Hasil penelitian ini berupa penjabaran data nilai skoring masing-masing variabel. Variabel tersebut adalah simpul lalu lintas, akses perpindahan moda, pelayanan terminal, dan manajemen lalu lintas. Keempat variabel tersebut di dalamnya terdapat sub variabel yang berbeda dan setiap sub variabel tersebut memiliki nilai yang juga berbeda.

1. Aksesibilitas terminal termasuk dalam kategori sedang dengan nilai 1. Dari data yang telah didapat dan dijabarkan pada bab sebelumnya, diketahui bahwa Terminal Giri Adipura terletak di jalan kolektor yang jika dilihat menurut indikator aksesibilitas tidak sesuai dengan Keputusan Menteri Perhubungan No 31 Tahun 1995 yang mengatur bahwa letak terminal tipe A seharusnya berada di jalan arteri dengan kelas jalan sekurangkurangnya kelas IIIA.

2. Efisiensi retribusi termasuk dalam kategori baik dengan nilai 3/2. Menurut indikator efisiensi retribusi, hasil perbandingan biaya untuk melakukan pemungutan dan realisasi retribusi hanya 4,9\%. Pemungutan ini dapat tercapai sesuai target karena upaya dari pengelola Terminal Giri Adipura dalam menertibkan bus maupun angkutan umum untuk masuk ke terminal.

3. Keterpaduan termasuk dalam kategori baik dengan nilai 1. Berdasarkan data yang sudah didapat, keterpaduan di Terminal Giri Adipura dapat dilihat dari pelayanan bus AKAP, bus AKDP, angkot, dan angkudes. Kinerja dari indikator tersebut termasuk pada kategori baik. Dalam Keputusan Menteri Perhubungan No 31 Tahun 1995 terminal tipe A harus melayani keempat angkutan umum tersebut untuk menjangkau perjalanan dalam kota dan luar kota.

4. Kapasitas termasuk dalam kategori sedang dengan nilai $2 / 3$. Berdasarkan data yang diperoleh, kapasitas parkir di Terminal Giri Adipura telah memenuhi standar untuk tiga jenis tempat parkir. Tempat parkir tersebut yaitu tempat parkir bus AKAP, bus AKDP dan kendaraan pribadi. Menurut keadaan ini, dapat dikatakan bahwa termasuk kategori sedang yaitu ditandai dengan kondisi terdapat 2 atau 3 ruang parkir yang memenuhi standar. Dua ruang parkir yang tidak memenuhi standar adalah ruang parkir untuk angkot dan angkudes.

5. Keteraturan termasuk dalam kategori sedang dengan nilai 2/3. Menurut Sistem Transportasi Nasional 2005, keteraturan dapat dilihat dari keberadaan angkutan berjadwal yang beroperasi. Dari hasil wawancara pada pihak Dinas Perhubungan, Komunikasi, dan Informatika Kabupaten Wonogiri, angkutan umum yang masuk ke Terminal Giri Adipura sebagian sudah memiliki time table yaitu bus AKAP dan AKDP. Namun saat ini pelaksanaannya belum dapat dilakukan secara optimal karena terdapat banyak permasalahan di kalangan pengusaha bus sehingga bus tidak dapat datang dan berangkat sesuai jadwal yang tercantum pada time table.

6. Keamanan termasuk dalam kategori baik dengan nilai 1. Berdasarkan data yang diperoleh dari indikator keamanan, di Terminal Giri Adipura sudah terdapat pos keamanan, kamera pengawas, dan empat petugas keamanan. Kondisi tersebut termasuk dalam kategori baik. Menurut Peraturan Menteri No 40 Tahun 2015, pelayanan keamanan terminal tipe harus tersedia pos keamanan, kamera pengawas, dan minimal dua orang petugas keamanan.

7. Kenyamanan termasuk dalam kategori sedang dengan nilai $2 / 3$. Dari hasil penilaian fasilitas terminal, didapatkan skor 57 yang berarti termasuk dalam kategori sedang dengan range 41,7 - 58,3. Dalam Sistem Transportasi Nasional (2005), disebutkan bahwa kenyamanan dapat diukur dari ketersediaan dan kualitas fasilitas terhadap standarnya. Sementara di Terminal Giri Adipura masih terdapat beberapa fasilitas yang 
tidak tersedia seperti menara pengawas, ruang informasi, dan telepon umum atau wartel. Selain itu, beberapa fasilitas tidak berfungsi dengan baik, seperti kios, toilet, mushola, rambu dan papan informasi, tempat parkir kendaraan umum serta tempat parkir kendaraan pengantar atau taksi.

8. Kesetaraan termasuk dalam kategori buruk dengan nilai 1/3. Dalam Peraturan Menteri Perhubungan No 40 Tahun 2015, standar pelayanan kesetaraan terminal tipe A yaitu ketersediaan ruang ibu menyusui, ramp check, kursi roda, dan toilet disabilitas. Pelayanan kesetaraan ini penting untuk menjangkau seluruh pengguna terminal termasuk ibu hamil atau menyusui dan penyandang disabilitas. Di Terminal Giri Adipura hanya terdapat fasilitas ruang ibu menyusui yang saat ini di dalamnya belum terdapat fasilitas yang layak seperti meja dan kursi.

9. Lancar dan cepat dengan dua parameter, yaitu sirkulasi di dalam terminal termasuk dalam kategori baik dengan nilai $3 / 2$ dan kelancaran lalu lintas di luar terminal termasuk dalam kategori sedang dengan nilai 1. Menurut Adisasmita (2011) dalam Dina dan Setiawan (2014), kelancaran dan kecepatan di dalam terminal diukur dari sirkulasi antara penumpang dan kendaraan. Di dalam Terminal Giri Adipura sendiri memang sirkulasi penumpang dan kendaraan sudah tertata serta waktu tunggu penumpang sebagian besar kurang dari 10 menit. Sedangkan di luar terminal hal yang sering dihadapi dalam perjalanan menuju Terminal Giri Adipura menurut persepsi sopir angkutan umum adalah kendaraan yang diparkir secara ilegal.

Kinerja yang dibahas dilihat dari tiap variabel fungsi Terminal Giri Adipura. Fungsi Terminal Giri Adipura terdiri dari empat variabel yaitu simpul lalu lintas, akses perpindahan moda, pelayanan terminal, dan manajemen lalu lintas.

1. Nilai skoring kinerja fungsi simpul lalu lintas berdasarkan indikator aksesibilitas dan efisiensi retribusi adalah 2,5 yang berarti termasuk dalam kategori baik. Berdasarkan dua indikator tersebut maka dapat dikatakan bahwa Terminal Giri Adipura sebagai simpul lalu lintas sudah memiliki kinerja yang baik karena cukup mudah untuk dijangkau dan sudah dimanfaatkan untuk tempat berkumpul dan menyebar dalam melakukan mobilitas sehari-hari baik penumpang maupun kendaraan.

2. Nilai skoring kinerja fungsi akses perpindahan moda berdasarkan indikator keterpaduan, kapasitas dan keteraturan adalah 2,33 yang berarti termasuk dalam kategori sedang. Hal yang perlu dilakukan pengelola Terminal Giri Adipura untuk meningkatkan kinerja adalah menyediakan kapasitas yang sesuai untuk angkutan kota dan angkutan desa. Selain itu, angkutan umum berjadwal semestinya dapat berjalan sesuai dengan time table yang ada sehingga penumpang bisa mendapatkan angkutan umum sesuai tujuan dalam waktu tertentu dengan mudah.

3. Nilai skoring kinerja fungsi pelayanan terminal berdasarkan indikator keamanan, kenyamanan dan kesetaraan adalah 2 yang berarti termasuk dalam kategori sedang. Pelayanan terminal semestinya dapat dirasakan oleh semua pengguna dari semua kalangan sehingga penyediaan fasilitas penting untuk dilakukan. Penambahan fasilitas yang perlu diadakan adalah ramp check, kursi roda, dan toilet untuk disabilitas. Selain itu, kelengkapan fasilitas kursi dan meja perlu ditambahkan di ruang menyusui.

4. Nilai skoring kinerja fungsi pelayanan terminal berdasarkan indikator lancar dan cepat adalah 2 yang berarti termasuk dalam kategori baik. Kondisi sirkulasi di dalam terminal dan lalu lintas di luar terminal sudah sesuai dalam mendukung kelancaran dan kecepatan di Terminal Giri Adipura. Manajemen lalu lintas yang perlu ditingkatkan adalah penertiban terhadap kendaraan yang diparkir secara ilegal atau tidak sesuai dengan tempatnya.

Hasil perhitungan skoring dari kinerja fungsi Terminal Giri Adipura dalam sistem transportasi di Kabupaten Wonogiri adalah 9,33. Berdasarkan kategori kinerja fungsi terminal, nila 9,33 berada pada range 6,68 9,35 sehingga termasuk dalam kategori kinerja sedang. Dengan demikian, kinerja fungsi Terminal Giri Adipura dalam sistem transportasi di Kabupaten Wonogiri belum mencapai kinerja baik dan perlu adanya 
beberapa hal yang harus dilakukan untuk dapat mencapai kinerja tersebut.

\section{KESIMPULAN DAN SARAN}

Kinerja fungsi Terminal Giri Adipura dalam sistem trasportasi di Kabupaten Wonogiri termasuk dalam kategori kinerja sedang karena tidak semua variabel mencapai kinerja baik. Variabel yang termasuk dalam kategori kinerja baik yaitu aksesibilitas dan manajemen lalu lintas. Sedangkan variabel yang termasuk dalam kategori sedang adalah pelayanan terminal dan akses perpindahan moda.

Sejauh ini, manaejemen lalu lintas yang dilakukan oleh pemerintah dengan pelaksanaan dari UPTD Terminal Giri Adipura dan Dinas Perhubungan, Komunikasi, dan Informatika Kabupaten Wonogiri sudah termasuk dalam kategori kinerja baik sehingga perlu dilanjutkan dengan konsisten. Kemudian terkait pelayanan terminal, perlu dikembangkan fasilitas keseta-raan yang menunjang kebutuhan ibu hamil dan menyusui serta penyandang catat.

\section{REFERENSI}

Adisasmita, Adji Sakti. (2011). Transportasi dan Pengembangan Wilayah. Yogyakarta: Graha Ilmu.

Ariola et al. (2006). Principles and Methods of Research. Manila: Rex Bookstore Inc.

Dina, An Nuurrika A. dan Setiawan, Wisnu. 2014. Evaluasi Purna Huni Sirkulasi dan Fasilitas Terminal Kartasura. Jurnal Sinektika. Program Studi Arsitektur Fakultas Teknik Universitas Muhammadiyah Surakarta.

Donelly, James H., Gibson, James L., and Ivancevich, John. (1994). Fundamental of Management. Texas: Business Publication.

Kementerian Perhubungan Republik Indonesia. (1995). Keputusan Menteri
Perhubungan No 31 Tahun 1995 tentang Terminal Transportasi Jalan.

Kementerian Perhubungan Republik Indonesia. (2005). Peraturan Menteri Perhubungan No. 49 Tahun 2005 tentang Sistem Transportasi Nasional.

Kementerian Perhubungan Republik Indonesia. (2015). Peraturan Menteri No 40 Tahun 2015 tentang Standar Pelayanan Penyelengaraan Terminal Penumpang Angkutan Jalan.

LPM-UGM. (1994). Studi Standardisasi Perencanaan Kebutuhan Fasilitas Perpindahan Angkutan Umum di Wilayah Perkotaan. Yogyakarta: LPM-UGM.

Morlok, Edward K. (1984). Pengantar Teknik dan Perencanaan Transportasi. Jakarta: Penerbit Erlangga.

Mustari, Yusni dan Kuddu, Dahri. (2011). Evaluasi Optimalisasi Pemanfaatan Terminal Angkutan Penumpang Umum (Studi Kasus Terminal Daya di Makassar). Prosiding. Jurusan Teknik Arsitektur Fakultas Teknik Universitas Hasanuddin.

Parapat, Renward dkk. (2005). Analisis Prioritas Faktor-Faktor yang Mempengaruhi Efektivitas Fungsi Terminal Amplas. Jurnal Atrium. Magister Teknik Arsitektur Universitas Sumatera Utara.

Pemerintah Kabupaten Wonogiri. (2011). Rencana Tata Ruang Wilayah Kabupaten Wonogiri Tahun 2011-2031.

Tamin, O. Z. (2000). Perencanaan dan Pemodelan Transportasi. Edisi II. Bandung: Penerbit ITB.

Warpani, Swarjoko. (1990). Merencanakan Sistem Perangkutan. Bandung: Penerbit ITB.

. Kamus Besar Bahasa Indonesia. http://kbbi.web.id/fungsi. Diakses pada 25 November 2016.

- Kamus Besar Bahasa Indonesia. http://kbbi.web.id/kinerja. Diakses pada 25 November 2016. 